\title{
Una mirada desde el realismo analítico: vieja metafísica, señorío de las verdades obvias y positivismo sospechoso*
}

\author{
A Look from the Point of View of Analytical Realism: Old \\ Metaphysics, Ruling Platitudes and Suspicious Legal Positivism
}

Pierluigi Chiassoni**

"The (pseudo) statements of metaphysics do not serve for the description of state of affairs [...] They serve for the expression of the general attitude of a person towards life".

Rudolf Carnap ${ }^{1}$

Recepción y evaluación de propuesta: 24/10/2017

Aceptación: 26/02/2018

Recepción y aceptación final: 20/12/2018

Resumen: El escrito busca proporcionar un análisis crítico, desde el punto de vista de un positivismo jurídico analítico y realista, de la filosofía y metafilosofía del derecho defendidas por Scott Shapiro en su libro Legalidad. Contiene cuatro partes. La primera parte ofrece una

* Traducción de Alejandro Calzetta, revisada por revista Discusiones.

** Profesor de Filosofía del derecho, Istituto Tarello per la Filosofia del diritto, Tarello Institute for Legal Philosophy, Università degli Studi di Génova. E-mail: pierluigi. chiassoni@unige.it. Versión ampliamente revisitada de Chiassoni, P., "Ruling Platitudes, Old Metaphysics, and a Few Misunderstandings About Legal Positivism", en Canale, D., Tuzet, G. (eds.), The Planning Theory of Law. A Critical Reading, Dordrecht - Heidelberg - New York - London, Springer, 2013, pp. 153-168.

1 Carnap, R., "The Elimination of Metaphysics Through Logical Analysis of Language", trad. de A. Pap (www.ditext.com/carnap/elimination.html) del artículo original "Überwindung der Metaphysik durch Logische Analyse der Sprache”, Erkenntnis, Vol. II, 1932. 
crítica de la ambición del libro de ofrecer una teoría "metafísica" que descubre "verdades filosóficas" acerca de "la naturaleza fundamental del derecho". La segunda parte contiene una crítica del uso que Shapiro hace de las "verdades obvias" al construir su teoría. La tercera parte considera críticamente, en dos pasos, la concepción del positivismo jurídico de Shapiro. La cuarta, y última, parte, pone en tela de juicio la solución que Shapiro ofrece para la "paradoja de la autoridad".

Palabras clave: filosofía del derecho, teoría analítica del derecho, metodología filosófica, positivismo jurídico, autoridad.

\begin{abstract}
The paper purports to provide a critical analysis of Scott Shapiro's philosophy and meta-philosophy of law as set forth in his book Legalidad, from the standpoint of a realistic and analytical legal positivism. It articulates into four parts. The first part contains a critique of Shapiro's "metaphysical" ambition of discovering "philosophical truths" concerning the "fundamental nature of law". The second part sets out a critique of the role Shapiro ascribes to truisms in the working out of his legal theory. The third, two-pronged, part concerns Shapiro's conception of a positivist theory of law. The fourth, and final, part provides a critical analysis of Shapiro's solution to the "Possibility Puzzle".
\end{abstract} Keywords: philosophy of law, analytical jurisprudence, philosophical methodology, legal positivism, authority.

\title{
I. Legalidad en tela de juicio
}

En Legalidad, Scott Shapiro confirma ser un filósofo del derecho muy bien preparado, prudente e imaginativo, además de sofisticado ${ }^{2}$.

Nos señala que su trabajo se sitúa en el marco de la "filosofía del derecho analítica" de corte positivista, que se contrapone a la "filosofía del derecho normativa". Esta última sería una empresa cognoscitiva que concierne al problema de la justificación moral del derecho, presentándose en una variante "interpretativa" y en otra "crítica"3.

2 Shapiro, S., Legalidad, Madrid-Barcelona, Marcial Pons, 2014.

3 Shapiro, S., op. cit., pp. 26-27. Sea dicho de paso, es dudoso, y en todo caso sujeto a discusión, que la filosofía normativa del derecho, a la luz de las tareas que Shapiro 
Una mirada desde el realismo analítico: vieja metafísica...

Cabe advertir, sin embargo, que las ideas que Shapiro tiene de la filosofía del derecho analítica y del positivismo jurídico resultan sospechosas desde la perspectiva de un positivismo analítico y realista -0 , por brevedad, de un realismo analítico- que puede atribuirse a maestros como Bentham, Austin, Kelsen y Ross. Las sospechas surgen apenas se consideren algunos puntos centrales de la teoría de Shapiro. En particular, los que atañen a la concepción de la filosofía analítica del derecho (la metafilosofía o metateoría del derecho), al rol de las verdades obvias (truisms, platitudes), al análisis conceptual y, en último lugar pero no por ello menos importante, a la separación entre ser y deber.

En cuanto a la metafilosofía, Shapiro parece encontrarse afectado por cierta nostalgia de la "vieja metafísica" o primera filosofía, que se presume capaz de obtener "verdades filosóficas" (una frase central en el libro de Shapiro) acerca de la "naturaleza fundamental del derecho", y capaz, por lo tanto, de proveer a la gente una forma más elevada de conocimiento, que se encuentra más allá del conocimiento empírico, que es fatalmente superficial ${ }^{4}$.

Además, en lo relativo al lugar que corresponde a las verdades obvias en la construcción de teorías, Shapiro parece adscribirles un rol "señorial", que tal vez va mucho más allá del requerido por una concepción crítica de la investigación filosófica ${ }^{5}$.

Estas dos posturas resultan en lo que, desde el punto de vista del realismo analítico, parece ser una concepción demasiado ambiciosa del análisis conceptual, pues Shapiro lo entiende como el medio que permite desenterrar las "verdades filosóficas" acerca de la "identidad" y las "propiedades necesarias" del derecho, de las cuales las verdades obvias son pruebas indiciarias".

Finalmente, en lo concerniente a la separación entre ser y deber, la ley de Hume, y la distinción entre cuestiones descriptivas y cues-

le adscribe, sea verdaderamente conocimiento: ya sea "de los fundamentos morales concretos del derecho vigente", ya sea de lo que el derecho, desde un punto de vista moral, "debería ser".

4 Shapiro, S., ibidem, pp. 26-27, 36 y ss.

5 Shapiro, S., ibidem, pp. 38-45.

6 Shapiro, S., ibidem, pp. 45-55, 59-63. 
tiones normativas, Shapiro parece estar bien al tanto de las mismas, y profundamente preocupado por superar el test que ellas plantean, o al menos tratar de escapar a las restricciones que ellas ponen. No obstante, su teoría del derecho como plan, es decir, su propuesta teórica original acerca de "la naturaleza fundamental del derecho", la que corresponde a la contribución propia de Shapiro al gran juego de la filosofía jurídica, parece darse de bruces contras esos pilares de la filosofía del derecho analítica.

En suma, vistas desde el realismo analítico, las posturas metafilosóficas y metodológicas arriba citadas han llevado a Shapiro a adoptar posiciones dudosas, las cuales consisten en (1) pasar por alto el objetivo, quizás modesto, pero valioso, de una clarificación y reconstrucción conceptual valorativamente neutral del discurso filosófico acerca del derecho, (2) avanzar una teoría del derecho que refleja una forma espuria de positivismo jurídico, (3) asumir una actitud indulgente respecto del positivismo jurídico excluyente, y, en fin, (4) presentar una solución sorprendente de la "paradoja de la autoridad".

Soy consciente de haber formulado cargos muy serios. En las secciones siguientes trataré de proporcionar algunos argumentos aptos para fundamentarlos.

\section{Vieja metafísica y señorío de las verdades obvias}

La teoría de las verdades obvias que Shapiro ofrece en su libro contiene dos ingredientes básicos: primero, un inventario de verdades obvias acerca del derecho; segundo, una afirmación metafilosófica acerca del papel que les corresponde en la construcción de (buenas) filosofías del derecho.

Shapiro nos provee de un inventario de "verdades obvias" o "truismos" ("platitudes") relativos al derecho, destacando cinco diferentes categorías:

1. Verdades obvias concernientes a las "instituciones jurídicas básicas" ("Todos los sistemas jurídicos tienen jueces", "Los tribunales interpretan el derecho", "Una de las funciones de los tribunales es 
resolver conflictos", "Todo sistema jurídico cuenta con instituciones para cambiar el derecho").

2. Verdades obvias concernientes a las "normas jurídicas" ("Algunas normas son reglas", "Algunas normas imponen obligaciones", "Las normas son siempre parte de los sistemas jurídicos", etc.).

3. Verdades obvias concernientes a la "autoridad jurídica" ("La autoridad jurídica es conferida por reglas jurídicas", "Las autoridades jurídicas tienen el poder de obligar, incluso cuando sus juicios son erróneos", etc.).

4. Verdades obvias concernientes a la "motivación" jurídica de las acciones individuales ("El simple conocimiento de que el derecho exige actuar de cierta manera no nos motiva a actuar de esa manera", "Es posible obedecer el derecho aunque uno no crea que está moralmente obligado a hacerlo", etc.).

5. Verdades obvias concernientes a la "objetividad" del derecho ("Existen respuestas correctas para algunas preguntas jurídicas", "A veces, los tribunales cometen errores al interpretar el derecho", "Algunas personas saben de derecho más que otras", etc.) ${ }^{7}$.

Sostiene, además, que toda investigación filosófica adecuada acerca del derecho debe tomar en serio estas verdades obvias, para así poder llegar, como ya he dicho, a las "verdades filosóficas" acerca de la naturaleza fundamental del derecho, lo que Shapiro considera como una cuestión de "metafísica" del derecho ${ }^{8}$.

La teoría de las verdades obvias, y la metafilosofía que la acompaña, merecen algunos comentarios.

(1) Adhiriéndose a una manera de pensar milenaria, Shapiro ve la "metafísica" como la rama del saber que se ocupa de las propiedades en virtud de las cuales una cosa es esa cosa y no otra cosa (por ejemplo, de las propiedades en virtud de las cuales alguna cosa es, digamos, una gaita y no un lavarropas), tratando, en particular, de "descubrir", sea la 
"identidad" de las cosas, sea las "implicaciones necesarias" del ser las cosas tales como son, es decir, sus "propiedades necesarias".

Por ende, la filosofía jurídica, en cuanto metafísica del derecho, tiene que descubrir la identidad del derecho y las propiedades necesarias del derecho: es decir, tiene que descubrir, sea las propiedades en virtud de las cuales una cosa es derecho, y no otra cosa (como sería, por ejemplo, tal cual sugiere Shapiro, algún sistema normativo totalmente idiosincrático que algún filósofo desee presentar-abusivamente- como derecho), sea las propiedades que necesariamente se siguen del ser el derecho derecho.

Cabe observar, sin embargo, que filósofos adherentes al realismo analítico procederían, en este punto, de un modo un tanto diferente.

Primero, los realistas analíticos comenzarían por analizar la mismísima cuestión concerniente a "la naturaleza del derecho"10. A diferencia de Shapiro, ellos no darían por sentado que preguntarse por "la naturaleza del derecho" significaría simplemente plantearse las preguntas que, sobre las huellas de la vieja metafísica, Shapiro se plantea. En cuanto analíticos y realistas, ellos comenzarían sus investigaciones planteando -a mi modo de ver, de un modo muy sensato- preguntas como las siguientes: ¿qué tipo de respuestas la gente espera de los filósofos del derecho, como respuestas adecuadas, cuando les preguntan acerca de "la naturaleza del derecho"? ¿Qué es lo que los filósofos del derecho, de hecho, hacen cuando tienen que lidiar con la cuestión de "la naturaleza del derecho"? ¿Qué es lo que los filósofos pueden estar buscando cuando se enfocan en "la naturaleza del derecho"? ¿Estamos seguros de que la investigación por "la naturaleza fundamental del derecho" tenga sentido (¿qué es, en efecto, la "naturaleza fundamental" de algo?)? ¿Estamos seguros de que la investigación sobre "la naturaleza fundamental del derecho", admitiendo que tenga sentido, sea "descubrimiento"?

Segundo, los realistas analíticos enfatizarían que, en lo que concierne al conocimiento de algo (pongamos, al conocimiento del fenómeno

9 Shapiro, S., op. cit., pp. 26-27.

${ }^{10}$ H. L. A. Hart ejemplifica la muy prudente actitud del analítico en este punto. Acerca de este aspecto del enfoque de Hart, ver, e. g., Chiassoni, P., "The Simple and Sweet Virtues of Analysis. A Plea for Hart's Metaphilosophy of Law", en Problema, 5, 2011, pp. 53-80, en las pp. 66-67. 
Una mirada desde el realismo analítico: vieja metafísica...

social del derecho), no hay un tercer tipo de cuestiones, además de las cuestiones factuales (empíricas), por un lado, y de las cuestiones conceptuales (que atañen a la construcción de los aparatos de términos y conceptos cognoscitivamente -más- adecuados para referirnos a los hechos que hemos investigado, observado, previsto), por el otro. Las llamadas cuestiones "metafísicas", siempre que la buena metafísica esté en juego, no son otra cosa más que cuestiones conceptuales, que, por supuesto, son tratadas a menudo en relación con cuestiones empíricas. Ahora bien, las cuestiones conceptuales tienen que ser encaradas y solucionadas mediante una forma adecuada de análisis conceptual. Es decir, mediante un análisis que incluya, a grandes rasgos, una etapa de detección y descripción conceptual, y, sobre la base de ello, una etapa de revisión o reconstrucción conceptual. Y cuya última etapa tiene que conducir a algún concepto filosófico que, por hipótesis, no es ni verdadero ni falso, pero debe estar justificado a la luz de algunos estándares de conveniencia teorética (o, si estamos en el marco de la filosofía de la justicia y de la política del derecho, de conveniencia práctica). De otro modo, una investigación "metafísica" sería una investigación misteriosa, que pretende proporcionar algún tipo de conocimiento "superior" y "profundo" acerca del derecho, tal como pretendía hacer la vieja (y mala) metafísica.

(2) En cuanto a las verdades obvias ("truismos", "verdades autoevidentes"), los realistas analíticos notarían que el rol que tienen en la filosofía (jurídica) no es en ningún sentido algo que esté asentado ni compartido. En efecto, añadirían ellos, se pueden destacar tres actitudes distintas en torno a esta cuestión.

Encontramos, para empezar, a los desconfiados de las verdades obvias. Para estos filósofos, las llamadas verdades obvias son a menudo prejuicios basados en el hábito y la falsa consciencia: modos de pensar simplistas, que deberían ser dejadas de lado en cualquier investigación filosófica que sea "bien ordenada", útil y genuina ${ }^{11}$.

${ }^{11}$ En sus Metaphysische Anfangsgründe der Rechtslehre de 1797 (trad. de Lizzaraga, G., Principios metafisicos del derecho, Librería de Victoriano Suarez, Madrid, 1873 - http:// fama2.us.es/fde/ocr/2006/principiosMetafisicosKant.pdf) Kant demuestra ser un caso claro de desconfiado de los truismos: él desconfía de los truismos porque son (supuestos) fragmentos de un conocimiento empírico a posteriori acerca del derecho. 
También encontramos, además, a los analistas de las verdades obvias. Estos filósofos creen que las verdades obvias pueden, de hecho, estar compuestas por prejuicios y falsa consciencia. También creen, sin embargo, que las verdades obvias se encuentran entre los puntos de partida necesarios para una investigación filosófica fructífera. Por supuesto, dicha investigación puede conducirnos a ver cómo muchos de estas verdades obvias son, de hecho, prejuicios carentes de base, creencias falsas, confusas, o de otro modo insostenibles, o incluso juicios cargados de valor y basados en el interés. Desde el punto de vista de los analistas (que es, pues, el punto de vista de los realistas analíticos), las verdades obvias están al servicio de la investigación filosófica, pero no vale el contrario; porque, de habernos conformado simplemente con las verdades obvias, no se hubiese llevado a cabo casi ningún progreso en el mundo físico ni en el moral ${ }^{12}$. Para ponerlo en otros términos: las verdades obvias, en este enfoque, son estímulos (inputs) de conocimiento útiles y, en efecto, hasta necesarias, para la investigación filosófica; son la principal fuente de dudas filosóficas, e impiden que las investigaciones filosóficas naveguen a la deriva. Los criterios que miden el éxito de una investigación filosófica, sin embargo, son independientes de las verdades obvias ("verdades obvias-independientes"). Los criterios de éxito son, en cambio, criterios de racionalidad, tales como los de la fundamentación empírica, de la determinación semántica, de la precisión conceptual, de la coherencia, de la desmitificación y de la fuerza explicativa ${ }^{13}$.

Para finalizar, están los crédulos de las verdades obvias. Para estos filósofos las verdades obvias son las puertas que conducen a las verdades filosóficas. Deben tomarse en serio, al pie de la letra, y ser objeto de explicaciones escrupulosas. Ellas dominan la investigación filosófica, de principio a fin, ya que señalan las propiedades naturales del objeto al que

${ }^{12}$ El método socrático de examen crítico y refutación es quizá el ejemplo más antiguo de esta actitud crítica hacia los truismos.

${ }^{13}$ Hans Kelsen, Karl N. Llewellyn, Herbert Hart y Norberto Bobbio, por mencionar a unos pocos, parecen compartir este enfoque en sus trabajos. 
se refieren. Ello en cuanto tienen en vista algún objeto único, y arrojan luz sobre él, capturando algunas de sus propiedades naturales y necesarias.

Ahora bien, Shapiro presenta su postura como cercana a la de los analistas ${ }^{14}$. Sin embargo, su manera de tratar a las verdades obvias acerca del derecho parece ponerlo en efecto más allá, en (o cerca de) el grupo de los crédulos de las verdades obvias.

Por un lado, Shapiro considera a las verdades obvias como la referencia definitiva de la genuina filosofía jurídica, pues asume que capturan, contienen o reflejan varios aspectos de la verdadera naturaleza del derecho y son por ende índices de la corrección de cualquier teoría filosófica acerca del derecho.

Por el otro, al redactar el inventario de las verdades obvias acerca del derecho que hemos visto antes, lo hace con escaso sentido crítico, no advirtiendo, antes que todo, que estas supuestas verdades obvias no son todas del mismo género, sino que forman un conjunto heterogéneo de afirmaciones.

Algunos de ellas parecen en efecto transmitir fragmentos de información genuina e incuestionable acerca de algunas características de los sistemas jurídicos positivos ("Todos los sistemas jurídicos tienen jueces", "Los tribunales interpretan el derecho", etc.), aunque también podrían funcionar como fragmentos de conceptos estipulativos de "derecho", "tribunales", "sistema jurídico", etc.

Otras supuestas verdades obvias, sin embargo, aunque se presenten como aserciones (fragmentos de un discurso en función descriptiva), resultan en cambio útiles para transmitir actitudes prácticas acerca de la manera -moralmente, estratégicamente, prudencialmente- adecuada de ver la práctica jurídica y de actuar en ella ("La autoridades jurídicas tienen el poder de obligar, incluso cuando sus juicios son erróneos", "Existen respuestas correctas para algunas preguntas jurídicas", "A veces, los tribunales cometen errores al interpretar el derecho"). En tales casos, las verdades obvias son, más bien, fragmentos de una ideología del derecho, y parece dudoso, por ende, asumirlas como criterios de corrección de las teorías del derecho.

${ }^{14}$ Shapiro, S., ibidem, pp. 41-44. 
Pierluigi Chiassoni

Otra señal del abandono de una postura adecuadamente crítica tiene que ver con lo siguiente. En efecto, de frente a las supuestas verdades obvias acerca del derecho que "todos" (nosotros incluidos) compartimos, surge una nueva pregunta: ¿de dónde vienen estas verdades obvias? ¿Cuándo aparecieron, y por qué? ¿Cuál es, en otros términos, su genealogía? Antes de darlas por sentado, parecería adecuado llevar adelante una investigación acerca de su pedigrí. Quizá algunas verdades obvias simplemente reflejan observaciones, creencias y actitudes razonadas y convergentes de "todos" respecto al derecho. Pero, por más incómodo que sea, no podemos descartar que algunas de tales creencias y actitudes podrían estar siendo adoptadas bajo el efecto de una mala filosofía y una falsa teoría; o bien a fuerza de una suerte de calambre mental; o aun más, debido a algún interés -material o ideológico-que nos empuja a creer en lo que creemos.

En suma, desde el realismo analítico, parece menester concluir que una bien entendida idea de corrección en la investigación filosófica aconseja encarar a las verdades obvias acerca del derecho con una mirada crítica, más fría que la que Shapiro parece adoptar. Tanto más fría, cuanto lo que se mira son (supuestas) verdades avaladas por el sentido común, que, como se sabe, es a menudo engañoso.

\section{Positivismo sospechoso: ¿es positivista la teoría del derecho como plan?}

Afirmé que Shapiro, aunque se profese positivista ${ }^{15}$, ha elaborado una teoría del derecho -el "positivismo acerca de los planes" o la "teoría del derecho como plan"- que, desde el realismo analítico, representa una instancia sospechosa de positivismo jurídico: algo que se parece más a una forma de positivismo espurio, de cuasipositivismo ${ }^{16}$ (supra, §1).

15 Shapiro, S., op. cit., p. 294: "La teoría de los planes es una explicación positivista que, en definitiva, fundamenta el derecho exclusivamente en hechos sociales".

${ }^{16}$ La expresión "cuasipositivismo" fue introducida, como es sabido, por Alf Ross en su crítica a la teoría pura del derecho, para resaltar el (supuesto) carácter paradójicamente normativo de la concepción kelseniana de la validez (Ross, A., "El problema de la 
Una mirada desde el realismo analítico: vieja metafísica...

Estos son cargos muy serios, los cuales deben sostenerse con argumentos igual de serios. No estoy completamente seguro de estar dotado con toda la seriedad necesaria para tal tarea. Ya veremos a medida que avance el argumento.

Lidiar con el "positivismo jurídico" es un asunto riesgoso. En efecto, como es bien sabido, una variedad de posturas heterogéneas (ideas, teorías plenamente desarrolladas, pretensiones, ideologías, actitudes, enfoques, etc.) van de la mano bajo esa etiqueta en la arena de la filosofía del derecho ${ }^{17}$.

Algunos filósofos analíticos (Hart, Bobbio, Ross, Scarpelli) a fines de la década de 1950 y a principios de la de 1960 trataron de identificar y destacar las más importantes de esas posturas, con el propósito, por un lado, de desarticular malentendidos y cualquier tipo de retórica cargada de emoción, y, por el otro, de despejar el camino para discusiones significativas e investigaciones fructíferas ${ }^{18}$.

Tomando en cuenta, y continuando, ese trabajo de análisis y desarticulación, podemos destacar seis posturas, con una o más de las cuales el "positivismo jurídico" puede ser -y de hecho ha sido-identificado de vez en cuando.

1. Formalismo (o legalismo) ético. Una primera postura que viaja bajo el nombre de "positivismo jurídico" es la teoría normativa (ideología, doctrina) relativa a la obligación política. Según esta teoría, los individuos tienen el deber moral de obedecer las normas jurídicas positivas, solo porque son normas jurídicas positivas. El deber puede considerarse, a su vez, o bien como (cuasi) absoluto o incondicio-

validez y el positivismo jurídico", 1961, en Ross, A., El problema de la validez y otros ensayos, México, Fontamara, 1969, pp. 7-46).

${ }^{17}$ He intentado proporcionar una reseña desapasionada de diferentes formas de "positivismo jurídico" en Chiassoni, P., El discreto placer del positivismo jurídico, Bogotá, Externado de Colombia, 2016, cap. I.

${ }^{18}$ Bobbio, N., Giusnaturalismo e positivismo giuridico, Milano, Comunità, 1965; Hart, H. L. A., "Legal Positivism", en Edwards, P. (ed.), The Encyclopedia of Philosophy, New York, Macmillan, 1967; Ross, A., op. cit.; Scarpelli, U., Cos'è il positivismo giuridico, Milano, Comunità, 1965. 
nal (Hobbes), o bien relativo o condicionado (Locke). Los nuevos iusnaturalistas pos Segunda Guerra Mundial tenían precisamente esta postura en mente cuando acusaban al "positivismo jurídico" de haber sido cómplice del régimen nazi y de otras dictaduras totalitarias y autoritarias.

2. Colaboracionismo doctrinal. Una segunda postura que viaja bajo el nombre de "positivismo jurídico" es la ideología profesional de acuerdo a la cual los juristas deben colaborar con cualquier régimen que domine su sociedad: los juristas, siendo los técnicos del derecho, deben estar al servicio del derecho, cualquiera que este sea y de donde sea que venga.

3. Custodia del Estado de derecho (ideología profesional de fidelidad al estado legislativo o constitucional). Una tercera postura que viaja bajo el nombre de "positivismo jurídico" es la ideología profesional de los juristas que trabajan en el marco o bien de un Estado de derecho democrático legislativo, o bien de un Estado de derecho democrático constitucional. Fija en ellos el deber, de ética o deontología profesional, de colaborar con estos sistemas jurídicos positivos, con el propósito de hacerlos más eficientes en las dos dimensiones, formal y sustantiva, del "gobierno de la ley" (rule of law) y de la garantía de los derechos fundamentales. No se trata pues, nótese, de una cooperación de meros sirvientes. Por el contrario, los juristas deben funcionar aquí de guardianes ilustrados: usualmente, con el propósito de proteger el Estado de derecho de políticos desconsiderados o canallescos.

4. Desarrollo de teorías generales y descriptivas del derecho positivo. Una cuarta postura que viaja bajo el nombre de "positivismo jurídico" consiste en (el desarrollo de) teorías generales del derecho positivo, que tienen por objeto dar cuenta de las actuales o posibles estructuras, ingredientes, y funciones de los sistemas jurídicos positivos. Esto es precisamente lo que los iuspositivistas analíticos vienen haciendo desde el cuarto final del siglo XVIII en adelante.

5. Epistemología empirista acerca del conocimiento del derecho en general. Una quinta postura que viaja bajo el nombre de "positivismo jurídico" 
consiste en un enfoque epistemológico ("metodológico", "conceptual") acerca del estatus y del método de la teoría jurídica. Aquí, el positivismo jurídico afirma que: (a) es valioso distinguir cuidadosamente entre el conocimiento objetivo y empírico del derecho positivo como en efecto es, por un lado, y su evaluación y crítica moral en virtud de alguna ideología acerca de cómo debería ser, por el otro; (b) los ordenamientos jurídicos positivos pueden ser objeto de fructíferas investigaciones empíricas; (c) mediante la comparación de varios ordenamientos jurídicos existentes, es posible desarrollar teorías generales acerca de sus ingredientes, estructuras, y funciones recurrentes (acerca de qué y cómo son, y cómo es que funcionan); (d) tomando en cuenta que el derecho es, en una parte relevante, un fenómeno lingüístico, compuesto por actos de habla, oraciones, palabras, y conceptos, una parte importante de la teoría del derecho debe lidiar, como decía Bentham, con la "terminología": i. e., con analizar y clarificar los conceptos básicos que encontramos en la mayoría de las experiencias jurídicas existentes.

6. Epistemología empirista acerca del conocimiento del contenido de sistemas jurídicos particulares. Una sexta, y para mis fines última, postura que viaja bajo el nombre de "positivismo jurídico" es la teoría de la ciencia jurídica según la cual la descripción de la existencia y del contenido de cualquier sistema jurídico positivo, para ser una genuina descripción, es cuestión de describir, desde el punto de vista externo de una sociología del discurso jurídico (hermenéutica), las prácticas que se autocualifican de creación de normas, aplicación de normas y cumplimiento de normas, tal cual estas son desarrolladas por los participantes del sistema jurídico (legisladores, jueces, funcionarios, juristas dogmáticos, meros ciudadanos, etc.), juntos con sus resultados.

Entre las seis posturas, las primeras dos tienen su origen en el pensamiento iusnaturalista y en la teología moral de poderosas instituciones religiosas, y representan formas de "positivismo" no "científico", sino "ideológico", con carácter de "idolatría" más o menos radical frente al derecho positivo en cuanto tal. La tercera postura representa, 
en cambio, una concepción "política" del positivismo jurídico, la cual surge históricamente en conexión con, y como complemento de, el positivismo estrictamente "científico"19. Es decir, del positivismo, representado por las posturas teoréticas y epistemológicas de (4) a (6), que se propone el establecimiento de un conocimiento científico (empírico, objetivo, exacto) del derecho positivo, sobre la base de una demarcación tajante, dentro de la cultura y la opinión jurídica, entre la teoría del derecho expositiva y la teoría del derecho censoria. Esto es, una demarcación entre el rol del expositor y el muy diferente, pero, nótese, no por ello menos importante, rol del censor; entre el conocimiento científico del derecho y la política del derecho.

Armados de este trasfondo, pasamos ahora a ver cuál es la forma de "positivismo jurídico" a la cual adhiere Shapiro, en su teoría del derecho como plan, y por qué, desde el realismo analítico, esa forma aparece sospechosa.

Aparentemente, Shapiro identifica al positivismo jurídico con una teoría acerca del concepto de derecho positivo. Se trataría, más precisamente, de una teoría que se propone definir el concepto de derecho de manera tal que la existencia y el contenido de las normas que componen un ordenamiento jurídico positivo cualquiera, respecto de cualquier cuestión de derecho que pueda surgir, sean susceptibles de un conocimiento objetivo y empírico.

Esta variedad de "teoría positivista", nótese:

a. se propone definir un concepto de derecho tal que proporcione una respuesta a dos problemas distintos: tanto al problema capital que debe abordar cualquier enfoque filosófico del derecho (¿qué es derecho?, ¿quid ius?), como al problema capital para cualquier agente que actúe o se proponga actuar bajo la jurisdicción de un ordenamiento jurídico positivo dado (¿cuál es el derecho acerca de...?, ¿quid iuris?) ${ }^{20}$;

${ }^{19}$ Abogan por un "positivismo político" Uberto Scarpelli (Scarpelli, U., op. cit.) y Luigi Ferrajoli (véase, por ejemplo, Ferrajoli, L., La democracia a través de los derechos. El constitucionalismo garantista como modelo teórico y como proyecto político, Madrid, Trotta, 2014). 
Una mirada desde el realismo analítico: vieja metafísica...

b. no es propiamente cientifica o epistemológica, aunque dependa de una epistemología jurídica empirista;

c. tampoco pertenece a algún tipo de axiología moral acerca del derecho; las normas jurídicas existentes pueden tener un contenido moralmente repugnante, y aun así ser "derecho", aunque un (muy) mal derecho ${ }^{21}$.

Entonces: ¿qué tipo de positivismo es el positivismo según Shapiro, si es que es alguno?

Por lo visto, comparece aquí algo de la vieja (y mala) metafísica. Nótese, en efecto, que, de acuerdo con Shapiro, la propiedad "ser susceptible de conocimiento objetivo", en cuanto propiedad que concierne a la existencia y al contenido de las normas jurídicas:

a. no es una propiedad, ni un objetivo, extrínseco, que el derecho, por así decirlo, recibe desde afuera, desde el mundo externo de los deseos e intereses contingentes de las personas;

b. es más bien, como la teoría del derecho como plan de Shapiro deja en claro, una propiedad, y un objetivo, intrínseco, que el derecho posee dentro de sí, y tal que podemos verlo una vez que entendemos su verdadera naturaleza, la cual se resume en la función de organizar y coordinar las conductas humanas por medio normas jurídicas-como-planes, al fin de hacer toda deliberación moral innecesaria para los sujetos ordinarios del derecho ${ }^{22}$.

El positivismo jurídico - en la versión de la teoría del derecho como plan- pretende ser, pues, una teoría general del derecho positivo que, por medio del concepto de derecho que la misma desarrolla (de clarísimo sabor Raziano), nos hace ver el derecho así como el derecho mismo, si es que fuese una entidad que hablase, nos sugeriría que lo veamos. Esto nos lleva, a su vez, a un concepto de derecho de acuerdo con el cual el derecho positivo consiste, en todo momento y lugar, en

${ }^{21}$ Shapiro, S., op. cit., pp. 230.

22 Shapiro, S., ibidem, caps. 6-13. 
los significados determinados, empíricamente cognoscibles, de las normas jurídicas (normas-como-planes) producidas por autoridades jurídicas competentes y capaces de planificar ${ }^{23}$.

Ahora bien: los partidarios de esta forma de positivismo jurídico parecen considerarlo una instancia genuina de positivismo teorético, descriptivo y avalorativo. A los ojos de un realista analítico, sin embargo, esta forma de "teoría positivista del derecho" resulta fatalmente engañosa ${ }^{24}$. Por las siguientes razones.

1. La teoría del derecho como plan nos proporciona un concepto de derecho relativamente estrecho, una vez que lo comparamos con otros conceptos de derecho teóricos en la tradición positivista. Piénsese, por ejemplo, al concepto de derecho de Hans Kelsen. Este concepto, estrictamente teórico general, no hace de la determinación semántica el test para establecer si "hay derecho" o no, acerca de un asunto determinado, sugiriendo que dicha cuestión está afuera de la competencia de una teoría del derecho genuinamente conforme al postulado de neutralidad valorativa.

Por un lado, de acuerdo con Shapiro, cuando la norma jurídica general a ser aplicada en un caso resulta indeterminada, no hay "derecho

${ }^{23}$ Shapiro, S., ibidem, pp. 316-318. En este último punto, en afirmar la coextensión entre el derecho vigente y el significado determinado de las normas jurídicas, de forma que, donde hay indeterminación, no hay (todavía) derecho, la teoría de Shapiro coincide con las teorías de Hart, Raz y Marmor. Véase Hart, H. L. A. (1961), The Concept of Law, Second Edition, Oxford, Oxford University Press, 1994, cap. VII, 272-274; Raz, J., Ethics in the Public Domain. Essays in the Morality of Law and Politics, Oxford, Clarendon Press, 1994, pp. 210-237; Raz, J., The Authority of Law. Essays on Law and Morality, Second Edition, Oxford, Oxford University Press, 2009, pp. 103-121; Marmor, A., Philosophy of Law, Princeton and Oxford, Princeton University Press, 2011, p. 136-159; Marmor, A., The Language of Law, Oxford, Oxford University Press, 2014, cap. 2.

${ }^{24}$ Esto pasa también, como es sabido, a los ojos de los "interpretativistas" capitaneados por Ronald Dworkin, quienes acusan a esta forma de positivismo jurídico de proporcionar, aunque de manera encubierta y quizás inconsciente, una teoría interpretativa, valorativamente comprometida, de rumbo convencionalista, acerca de lo que el derecho, en cada momento, dispone. Véase Dworkin, R., Law's Empire, London, Fontana, 1986; Stavropoulos, N., "Legal Interpretivism", en Stanford Encyclopedia of Philosophy, First Published Tue Oct 14, 2003; substantive revision Tue Apr 29, 2014. 
que conocer". Esto es así porque, o bien el derecho provee una respuesta clara al caso en cuestión, que es susceptible de conocimiento objetivo, empírico, basado en hechos sociales como los usos lingüísticos o la intención legislativa, o bien no hay derecho para tal caso ${ }^{25}$.

Por el otro, de acuerdo a Kelsen, las normas jurídicas generales siempre son semánticamente indeterminadas, a la luz de los diversos métodos de interpretación disponibles en nuestros sistemas jurídicos. Desde un punto de vista teórico, sin embargo, dicha situación no significa que no hay derecho que conocer. Por el contrario, hay algo que puede ser conocido y que delimita los bordes más extremos del derecho positivo para un caso: y este es el marco (Rahme) de las diversas interpretaciones alternativas, metodológicamente posibles, de la norma general en juego ${ }^{26}$.

En la visión de Shapiro, el derecho en relación a un caso está siempre, desde un punto de vista interpretativo, o bien determinado, y entonces hay derecho para ser conocido y aplicado, o bien indeterminado, y entonces no hay derecho para ser conocido y aplicado ${ }^{27}$.

En la visión de Kelsen, en cambio, el derecho preexistente respecto de un caso dado se encuentra siempre indeterminado, desde el punto de vista de la interpretación y la aplicación futuras. Esto no quiere decir que no hay derecho; quiere decir, más bien, que nos vemos confrontados, al menos desde un punto de vista metodológico, con un exceso de riqueza, que refleja la fatal indeterminación que afecta a la producción de normas "inferiores" sobre la base de, y aplicando, normas "superiores"28.

Para Shapiro, el derecho preexistente coincide estrictamente con el producto determinado de los métodos interpretativos. En este sentido, hay derecho, si, y solo si, todos los métodos interpretativos disponibles se apoyan en investigaciones fácticas y apuntan a un mismo y claro resultado (derecho $=$ fuentes autoritativas + los productos interpretativos unívocos y determinados que pueden obtenerse a partir de las mismas) $)^{29}$.

${ }^{25}$ Shapiro, S., op. cit., pp. 310-318.

${ }^{26}$ Kelsen, H., Reine Rechtslehre, Zweite Aufgabe, Wien, Deuticke, 1960, cap. VIII.

27 Ibidem.

${ }^{28}$ Ibidem.

${ }^{29}$ Ibidem. 
Contrariamente, para Kelsen, las normas generales preexistentes, además de estar acompañadas por la cláusula alternativa tácita, siempre son "productos semiacabados", que necesitan ser ("auténticamente") acabados por los órganos de aplicación (derecho = fuentes autoritativas + cualquier producto interpretativo que los órganos de la aplicación pueden obtener de las mismas).

Aparentemente, nos vemos enfrentados a dos visiones diferentes acerca del mismo fenómeno. Ahora bien: ¿cuál de estas dos visiones deberíamos aceptar desde un punto de vista estrictamente teórico?

Seguramente podríamos meramente dar cuenta de la diferencia y detenernos allí. Si, en cambio, nos preguntamos por alguna justificación pragmática, si es que hay alguna, para tal diferencia, llegamos aparentemente a la siguiente conclusión.

La visión proporcionada por Kelsen parece encontrarse más en sintonía con el ideal de una teoría jurídica puramente descriptiva y libre de valoraciones, la cual rechaza metódicamente toda tentación de incluir en su reconstrucción del derecho cualquier característica que sea dependiente de evaluación alguna. Por esta razón, Kelsen sostiene que las normas jurídicas generales son siempre indeterminadas, desde el punto de vista de los métodos interpretativos, sea cuando ellas tienen que ser usadas por los jueces para resolver un caso, sea cuando se trate de manejarlas, por los juristas y abogados, para formular propuestas acerca de cómo resolver casos.

La visión proporcionada por Shapiro, contrariamente, parece preocupada con presentar al derecho como una empresa racional. E1 concepto de derecho de la teoría del derecho como plan está tan estrechamente definido, podría decirse, solo con el propósito de presentar al derecho como algo que satisface las presuntas necesidades prácticas de los individuos, concebidos como agentes planificadores. La teoría del derecho de Shapiro está, por ende, comprometida con el valor, o estándar práctico, de la racionalidad de medios a fines del derecho en relación al fin de proporcionar planes cuya identificación no requiera argumentación moral. 
2. Shapiro parece resistirse a una interpretación tal de su teoría. En efecto, el concepto de derecho de la teoría del derecho como plan es presentado como el núcleo de una descripción (metafísica) de cómo, en general, es el derecho ${ }^{30}$.

Desafortunadamente dicha "descripción" es, por así decirlo, teleológica en vez de funcional: está basada en la idea de que hay una verdadera, principal y esencial función del derecho y que la teoría jurídica, en cuanto investigación metafísica sobre la naturaleza fundamental del derecho, puede descubrirla, y, una vez descubierta, debe sacar todas las consecuencias que de ella se siguen.

Sin embargo, para quien asuma la perspectiva del realismo analítico, la idea que haya una verdadera y esencial función del derecho va más allá de los límites de una genuina investigación empírica y valorativamente neutral, y claramente pertenece al reino de las valoraciones, incluso cuando se trate de valoraciones en términos de racionalidad o irracionalidad instrumental de un conjunto normativo.

En suma: a los ojos de un realista analítico, la pretendida teoría positivista de Shapiro es un amasijo de hechos y de valores, algo que tiene el sabor antiguo de los tiempos pre-benthamianos. Representa en efecto el resultado de una filosofía del derecho que pretende ser ejercicio de genuina, a-valorativa, metafísica, pero que de hecho tiene carácter de propuesta ético-normativa (la teoría de los planes). De modo tal que transforma el objetivo epistemológico del positivismo científico (proporcionar un conocimiento empírico, objetivo y exacto del derecho positivo tal cual es), en un rasgo ontológico del derecho positivo mismo ${ }^{31}$. A pesar de sus pretensiones, esta teoría, en lugar de ser de una forma mejorada de positivismo, como sugiere Shapiro, es un ejemplo de cuasipositivismo, de circunfusa teleología metafísica y de valoraciones disfrazadas de verdades filosóficas.

${ }^{30}$ Shapiro, S., op. cit., pp. 26-28.

31 Shapiro, S., ibidem, pp. 55-56. 


\section{Positivismo sospechoso: ¿una capa de barniz para el positivismo jurídico excluyente?}

La teoría del derecho como plan se coloca en el marco del así llamado positivismo jurídico excluyente (PJE) ${ }^{32}$. Las tesis básicas del PJE, de acuerdo a Shapiro, son las siguientes.

1. Una norma es considerada derecho si, y solo si: (a) tiene un origen (pedigrí) social, y (b) es aplicable sin la necesidad de recurrir al razonamiento moral. Estas dos ideas corresponden a la tesis del "Carácter excluyente" y a la tesis del "Carácter último": "los hechos jurídicos están determinados exclusivamente por hechos sociales" y, por lo tanto, "los hechos jurídicos, en última instancia, están determinados exclusivamente por hechos sociales"33.

2. La teoría de Dworkin acerca de la adjudicación de los casos difíciles está equivocada (pues "malinterpretó la evidencia"): el comportamiento judicial en los casos difíciles no muestra ni que el formalismo sea verdadero, ni que los jueces carezcan de discreción fuerte ${ }^{34}$.

3. En los casos difíciles, cuando las normas preexistentes dotadas de pedigrí se han "agotado", "los jueces [...] simplemente tienen una obligación jurídica de aplicar estándares extra-jurídicos [...], el hecho de que los jueces [...] tengan la obligación de aplicar normas sin pedigrí no implica que estén obligados a aplicar derecho preexistente; en lugar de ello, sencillamente tienen una obligación de ir más allá del derecho y aplicar las normas de la moral"; esto significa, en otras palabras, que "cuando los estándares con pedigrí se agotan, los jueces [...] tienen simplemente la obligación jurídica de ejercer una discreción fuerte,

32 Shapiro, S., ibidem, pp. 333 y ss., 333 nota 16.

${ }^{33}$ Shapiro, S., ibidem, p. 331.

34 Shapiro, S., ibidem, p. 334. 
Una mirada desde el realismo analítico: vieja metafísica...

observando la moral más allá del derecho para resolver el caso que les ocupa"35.

Centrémonos en la tercera tesis del PJE. Ahora bien: desde un punto de vista metateórico, el PJE, si pretende ser una teoría general de la adjudicación de los casos difíciles, es claramente falso. Aunque, por supuesto, puede tener cierta utilidad como teoría descriptiva de un contexto institucional específico (un fragmento de particular jurisprudence), sea como ejemplo de una teoría normativa del derecho: es decir, como ejemplo de una teoría que postula un modelo ideal de derecho, un modelo de lo que el derecho debería ser. Para una conclusión tal se pueden aducir las siguientes razones.

1. Lo que los jueces deban jurídicamente hacer ante los casos difíciles, a saber, el contenido de su obligación jurídica, si hay alguna, ante tal predicamento, puede ser ya sea una cuestión para una teoría del derecho descriptiva y local, que dé cuenta de algunos ordenes jurídicos, observando cómo estos funcionan desde el punto de vista de sus participantes, ya sea una cuestión para una teoría normativa del derecho que fije dicho deber, según los casos, como propuesta interpretativa (de iure condito), o bien como propuesta legislativa (de iure condendo). No hay una tercera alternativa más allá de las dos mencionadas. Puede ocurrir, por supuesto, que uno pretenda derivar la existencia de un deber jurídico dado del concepto mismo y "verdadero" de derecho, o bien de la naturaleza misma y "verdadera" del derecho. Se trataría, empero, de una pretensión ilusoria, ya que, desde cualquier punto de vista razonable, se trataría solo de una propuesta normativa relativa a los deberes del juez, avanzada (y

${ }^{35}$ Shapiro, S., op. cit., pp. 334, 335; p. 336: "Tanto el positivista excluyente como el incluyente coinciden en que los jueces tienen la obligación de aplicar normas morales una vez se agotan las normas con pedigrí. Simplemente discrepan acerca de cómo describir lo que están haciendo: para el positivista jurídico incluyente, los jueces están aplicando normas jurídicas; para el positivista jurídico excluyente, están creando normas jurídicas". 
disfrazada) bajo el amparo del mito de un concepto verdadero (conceptualismo), o de una naturaleza verdadera (pensamiento iusnaturalista), del derecho, que dictan a los jueces sus deberes.

2. Puede ocurrir -y de hecho ha ocurrido en la historia de las instituciones jurídicas-que, en un sistema jurídico, los jueces tengan simplemente la obligación de evitar cualquier tipo de decisión en un caso dudoso. Por ejemplo, puede ser que deban rechazar los reclamos de las personas involucradas, actores, demandados y fiscales por igual (obligación de non-liquet). Alternativamente, en los casos difíciles, los jueces pueden tener también la obligación de suspender su pronunciamiento y referir el asunto a la legislatura, solicitándole el dictado de una norma apropiada al caso (obligación de référé législatif).

Estas simples observaciones sugieren algunas conclusiones.

Primero, lejos de exponer o bien la falsedad (en cuanto teoría general), o bien la especificidad contextual (o incluso la naturaleza no teorética y no descriptiva, sino -encubiertamente- prescriptiva), de la pretensión del PJE relativa a la obligación de los jueces frente a casos difíciles, lejos de, en otras palabras, desmitificarla, nuestro autor-cómo Bentham habría dicho- tranquilamente ha presentado dicha pretensión como una verdad evidente: simplemente la cubrió con una capa de barniz, por decirlo de alguna manera.

Segundo, ya que la teoría del derecho como plan -la propia teoría de Shapiro- sigue en este punto la orientación dada por el PJE, esta también fracasa, en cuanto teoría general y genuinamente descriptiva, respecto de la cuestión central de los casos difíciles.

Tercero, puesto que ni el PJE ni la teoría del derecho como plan consentirían ser presentadas como teorías locales, que describen contextos institucionales determinados, ellas son, o bien teorías genuinamente generales, pero falsas; o bien teorías del derecho no ya descriptivas, sino normativas, y, más precisamente, interpretativas, aunque encubiertas. 


\title{
V. Un poco de realismo acerca de la "Paradoja de la autoridad"
}

\begin{abstract}
[L]a Paradoja de la autoridad [dice Shapiro] intenta mostrar que la autoridad jurídica es imposible. Por una parte, la autoridad jurídica tiene que ser conferida por normas jurídicas; por otra parte, sin embargo, las normas jurídicas deben ser creadas por la autoridad jurídica. De estos dos presupuestos, obtenemos la clásica paradoja del huevo y la gallina. Cada vez que intentamos determinar una afirmación sobre la autoridad jurídica, o bien entramos en un círculo vicioso (la autoridad creó la norma que le confirió la potestad de crear esa misma norma) o bien caemos en un regreso al infinito (la autoridad obtuvo su potestad de otra autoridad, que obtuvo la suya de otra autoridad, y así sucesivamente) $)^{36}$.
\end{abstract}

Shapiro se toma en serio la paradoja de la autoridad y cree haber encontrado en su teoría del derecho como plan la clave para resolverla. Es más, cree haber encontrado la solución en una concepción de la autoridad jurídica basada en la concepción del ser humano como agente planificador. El ser humano -afirma Shapiro- es animal planificador; los grupos de seres humanos son grupos de planificadores, y en tales grupos se encuentran planes "maestros" (planes para hacer planes) y planes "derivados". He aquí la solución que Shapiro propone: "la autoridad jurídica es posible porque ciertos tipos de agentes son capaces de (1) crear y dar forma a un plan para planificar y (2) motivar a otros a observar sus planes" 37 .

Shapiro precisa que la autoridad jurídica es "posible" bajo dos condiciones: la condición de autorización y la condición de capacidad para planificar (a la que alude en el pasaje apenas citado).

En lo que concierne a la primera condición de posibilidad de la autoridad jurídica (y de los sistemas jurídicos), a saber, la condición de 
Pierluigi Chiassoni

autorización, Shapiro resume la esencia de su argumento en las siguientes líneas:

la Teoría de los planes es capaz de justificar la existencia de reglas jurídicas fundamentales [las reglas que le confieren a alguien los máximos poderes jurídicos para crear planes para otros] sin generar círculos viciosos o regresos al infinito. Los funcionarios públicos tienen la potestad de adoptar el plan compartido que establece estas reglas fundamentales en virtud de las normas de la racionalidad instrumental. Puesto que estas normas que confieren la capacidad racional de planificar no son planes ellas mismas, no han sido creadas por ninguna autoridad. Existen solo en virtud de que son principios racionalmente válidos ${ }^{38}$.

En cuanto a la segunda "condición de posibilidad" de la autoridad jurídica (y de los sistemas jurídicos), a saber, la condición de capacidad para planificar, Shapiro afirma: "que esta condición tenga lugar tampoco genera desconcierto" 39 .

Desde el realismo analítico, sin embargo, la manera de proceder de Shapiro resulta dudosa.

Por un lado, Shapiro no se da cuenta, aparentemente, de que la paradoja de la autoridad, en cuanto instancia de la paradoja huevo-gallina respecto de la autoridad jurídica, está, para decirlo así, mal planteado, puesto que no merece ser tomado en serio, sino para poner bajo la luz el error en que caen los que la toman en serio.

Por el otro lado, la solución que Shapiro propone para la paradoja resulta, a decir poco, sorprendente, tenida en cuenta la profesión de fe positivista que acompaña la teoría del derecho como plan.

\section{V.1. Un problema mal planteado}

Si se observa con atención, la "autoridad jurídica" sobre la cual versa La Paradoja de la autoridad, tal como la presenta Shapiro, es, y no

\footnotetext{
38 Shapiro, S., op. cit., pp. 228-229.

39 Shapiro, S., op. cit., p. 229.
} 
puede ser sino, el poder "originario" o "constituyente". Es decir, el poder que, en términos kelsenianos, produce la primera constitución histórica de un ordenamiento jurídico. La primera constitución, a su vez, identifica habitualmente un conjunto de autoridades jurídicas "constituidas", que empero son supremas en relación al ordenamiento jurídico así constituido. Estas autoridades son pues, para decir así, las gallinas que nacen del huevo de la primera constitución. Pero, nótese bien, la primera constitución histórica, así entendida, no concierne al poder constituyente: no autoriza al poder constituyente a constituir la primera constitución. La paradoja huevo-gallina, con las dos (no-)soluciones consideradas por Shapiro, de la auto-autorización y del regreso al infinito, surge, si se piensa como parece pensar Shapiro, que el poder constituyente, para poder ser un poder jurídico, tiene a su vez que estar autorizado (es decir "constituido") por una norma de autorización: tiene que ser otra gallina que nace de otro huevo. Pero ni una gallina puede poner el huevo del cual ella misma nace, ni podemos pensar en una serie infinita de gallinas y de huevos. Resulta evidente, por ende, que la paradoja huevo-gallina, en relación al poder constituyente de un ordenamiento jurídico, está mal planteada, es el fruto de un calambre mental. El carácter jurídico del poder constituyente, siendo originario, no depende (ni puede depender) de una autorización. En un sinsentido preguntarse, como hace Shapiro, por aquello que lo autoriza. Simplemente, el poder constituyente es jurídico, porque, si es exitoso, produce la primera constitución e identifica las autoridades constituidas supremas, de un ordenamiento jurídico determinado.

\section{V.2. Una solución sorprendente}

Con las precisiones apenas formuladas, volvamos a considerar la solución que Shapiro propone para la paradoja de la autoridad. Para comenzar, puede concederse que la condición de capacidad para planificar pueda en efecto darse, siendo una pura cuestión de hecho. En lo que respecta a la condición de autorización, vale la pena leer nuevamente el pasaje crucial de Shapiro: 
Pierluigi Chiassoni

la Teoría de los planes es capaz de justificar la existencia de reglas jurídicas fundamentales [las reglas que le confieren a alguien los máximos poderes jurídicos para crear planes para otros] sin generar círculos viciosos o regresos al infinito. Los funcionarios públicos tienen la potestad de adoptar el plan compartido que establece estas reglas fundamentales en virtud de las normas de la racionalidad instrumental. Puesto que estas normas que confieren la capacidad racional de planificar no son planes ellas mismas, no han sido creadas por ninguna autoridad. Existen solo en virtud de que son principios racionalmente válidos ${ }^{40}$.

Ahora bien, la solución que Shapiro propone es, desde el realismo analítico, sumamente sorprendente. Debe advertirse que se propone resolver la paradoja de la autoridad apelando a un conjunto de normas de racionalidad instrumental que (a) confieren poderes a los "funcionarios jurídicos" (supremos) y (b) cuya existencia, cabe notar, depende únicamente de su contenido. Son normas que existen, afirma Shapiro, "solo en virtud de que son principios racionalmente válidos". Es decir, presumiblemente, principios que "valen", que "deben ser obedecidos", que "vinculan", en virtud de su contenido conforme a la idea de racionalidad instrumental.

¿Qué tipo de argumento es el argumento de Shapiro? ¿Realmente resuelve el problema, como pretende Shapiro?

Desde mi punto de vista, el argumento de Shapiro puede entenderse de tres maneras diferentes: primero, como argumento trascendental; segundo, como argumento hegeliano; tercero, como argumento iusnaturalista.

El argumento trascendental. Como argumento trascendental, el argumento de Shapiro sería, más o menos, así:

1. Las normas de racionalidad instrumental son condiciones necesarias de la existencia de la "autoridad jurídica". Si ellas no existieran, tampoco existiría la "autoridad jurídica".

2. Pero la "autoridad jurídica" existe. 
Una mirada desde el realismo analítico: vieja metafísica...

3. Ergo, las normas de racionalidad instrumental también existen.

Desafortunadamente, si fuera un argumento trascendental, el argumento de Shapiro no daría la talla contra la paradoja de la autoridad pues resultaría, claramente, circular. De hecho, una de sus premisas, que la "autoridad jurídica" existe, es precisamente lo que Shapiro quiere probar.

El argumento hegeliano (Hegel golpea de nuevo). Como argumento hegeliano, el argumento de Shapiro sería, más o menos, así:

1. Cualquier cosa que es real es racional, y cualquier cosa que es racional es real.

2. Las normas de racionalidad instrumental son racionales.

3. Ergo, las normas de racionalidad instrumental son reales.

Una vez que, despertándonos, escapemos al hechizo del Gran Circo Hegeliano, podemos apreciar que el pretendido argumento equivale a afirmar que las normas de racionalidad instrumental existen porque nos gustan, las deseamos, las elegimos, las necesitamos. Su existencia como principios "racionalmente válidos" es aquí nada menos que el resultado de una jugada práctica: nosotros -agentes morales autónomoslas introducimos en escena porque ellas son herramientas que necesitamos para establecer, para hacer posible, la "autoridad jurídica".

El argumento iusnaturalista. Finalmente, como argumento iusnaturalista el argumento de Shapiro sería, más o menos, así:

1. Si los hombres son animales planificadores (es decir, tienen la capacidad y la disposición a hacer planes para sí y para otros), entonces existen normas de racionalidad instrumental (principios racionalmente válidos) que representan el costado normativo natural de dicho rasgo de la naturaleza humana.

2. Los hombres son animales planificadores.

3. Ergo, existen normas de racionalidad instrumental (principios racionalmente válidos) que representan el costado normativo natural de dicho rasgo de la naturaleza humana.

Desafortunadamente, sin considerar la dificultad de aceptar cualquier pretensión iusnaturalista, esta forma de escape parece inviable 
para Shapiro. ¿Cómo puede consistentemente basar su teoría del derecho como plan, en cuanto teoría positivista del derecho, en principios de derecho natural (aunque solo sean principios de racionalidad instrumental)? Claramente, esta solución la paradoja de la autoridad se ubica fuera de los confines de una teoría positivista, general y descriptiva, del derecho, y pertenece más bien, sea Shapiro consciente de eso o no, al ámbito de la ciencia de la legislación (Austin), en su dimensión de justificación práctica del derecho positivo, o bien al ámbito de la filosofía de la justicia y de la política del derecho (Kelsen).

\section{V.3. La (di)solución realista de la paradoja}

Asumiendo una mirada realista, no queda más que concluir que la pretendida solución de Shapiro a la paradoja de la autoridad es meramente una farsa, una ilusión, basada, como hubiera señalado Austin, en una trama de discursos inciertos.

¿Puede, de hecho, resolverse tal paradoja? ¿Acaso el fracaso de Shapiro muestra que no tiene solución?

Ya hemos visto que la paradoja está mal planteada (supra, § 5.1). Sin embargo, for argument's sake, merece la pena ensayar una estrategia de escape, que equivale, más o menos, a disolverla. Para mostrar cómo podría diseñarse esa estrategia, me referiré al relato de Shapiro acerca de los dos hijos del poderoso rey Lex, Positivo, quien le sucedió en el trono, y Natural, quien en cambio fue excluido del poder, donde la paradoja de la autoridad es el eje alrededor del cual se consuma la tragedia.

He aquí el relato:

Tras algunos años de reinado, Positivo modificó la regla del diezmo para aumentar la cantidad de granos que cada miembro del grupo debía contribuir al almacenamiento común. Como nadie estaba satisfecho con esta decisión, Natural vio la oportunidad de desafiar la potestad de Positivo. Durante la siguiente reunión de la aldea, natural se puso de pie y anunció que no obedecería la nueva regla del diezmo. "Pero Natural", protestó 
Una mirada desde el realismo analítico: vieja metafísica...

Positivo, "yo soy quien crea las reglas y tú tienes la obligación jurídica de obedecerme".

[...] En respuesta a las quejas de Positivo, Natural expuso la misma paradoja sobre la posibilidad de la autoridad jurídica con la que Phil [el filósofo de la tribu] había sorprendido a su padre algunas décadas antes: ¿cómo puede Positivo tener la autoridad jurídica de crear reglas, cuando se requieren reglas para conferir semejante autoridad y la autoridad para crear reglas? [...] Positivo argumentó que la autoridad jurídica en última instancia depende del poder político. Como tiene la habilidad de castigar a quienes no paguen el diezmo, tiene entonces el derecho jurídico de imponerles la obligación de obedecer. Pero Natural tenía una contestación para esto: "el mero hecho de que puedas castigarme es solo un hecho descriptivo [sic] del mundo. Tu afirmación simplemente describe lo que es el caso. No obstante, para que yo esté jurídicamente obligado a obedecerte, tú debes demostrar que jurídicamente se te debe obediencia. Como no es posible deducir lo que debe ser a partir de lo que es, de aquí se implica que no puedo estar jurídicamente obligado a obedecerte".

Positivo concedió que Natural tenía razón, pero intentó plantear otra idea [...]. La autoridad jurídica, de acuerdo con esta visión alternativa, deriva de la práctica de deferencia de los miembros del grupo. Positivo tiene autoridad jurídica para obligar porque todos consideran que tiene esa autoridad. Pero Natural ofreció la misma respuesta: "Decir que todos piensan que tienes el derecho de ordenarle qué hacer es solo formular un enunciado descriptivo del mundo. Por otra parte, inferir que realmente tienes un derecho jurídico es extraer una conclusión normativa. Los enunciados normativos nunca pueden deducirse de simples enunciados descriptivos". Positivo comprendió el argumento de Natural y no supo qué responder. Entonces, hizo lo que los gobernantes han hecho a lo largo de la historia 
con los disidentes que dicen cosas que tienen sentido: Positivo hizo que [Natural] fuera ejecutado ${ }^{41}$.

Así que, aparentemente, Positivo no tenía forma de escapar a los argumentos de Natural -aunque, por supuesto, la ejecución de Natural no era de ninguna manera el único final posible-.

Tal vez, sin embargo, contrariamente a lo que sugiere Shapiro, Positivo pudo haber apelado a una vía de escape efectiva y razonable a los argumentos de Natural, y, además, distinta de la que provee la teoría de los planes (es decir, alternativa a asumir la vigencia de misteriosos principios de racionalidad instrumental), que, como ya hemos visto, funciona al precio de adoptar un enfoque iusnaturalista.

Tengo la sospecha de que ambos hermanos cayeron bajo la influencia de un pésimo consejero. Phil, el filósofo de la tribu, jugó un rol central en la tragedia y debe ser considerado moralmente responsable. Natural, de no haber estado cegado por el resentimiento que le produjo haber sido excluido por Lex del poder, habría debido estar más atento a los trucos de Phil. Positivo, también, habría debido notar que algo no funcionaba en los argumentos de Natural (y de Phil). En suma, ellos, y su padre antes que ellos, tuvieron la mala suerte de tener en su comunidad un filósofo como Phil, confundido y provocador de confusión a la vez. En cambio, de haber estado a mano Anfry (el viejo amigo Analysis Freak), el resultado de la discusión entre Natural y Positivo probablemente hubiera sido distinto, como sugeriré a continuación.

Anfry es, por supuesto, un realista analítico. Esto es, más o menos, lo que, de haber estado presente, Anfry habría sugerido a Positivo y a Natural para calmarlos.

1. Frente al derecho, dos posturas básicas, dos juegos básicos, están disponibles: el del jugador (participante) y el del observador.

2. El del jugador es un juego comprometido, práctico. Para jugar, tenemos que tomar decisiones sobre quién juega qué papel; qué es lo que cada papel involucra en términos de derechos, deberes, poderes, etc.; cuándo, si es que alguna vez, y cómo las reglas 
producidas por el creador de las mismas pueden ser impugnadas, etc.

3. El juego del observador es, en cambio, un juego de conocimiento. Se trata de conocer, en los hechos y en la mejor medida posible, cómo funcionan, cuándo comienzan y son jugados, etc., los juegos sociales que llamamos derecho.

4. E1 positivismo jurídico, en las posturas epistemológicas y teóricas mencionadas más arriba (supra, § 3), persigue el objetivo de ofrecer a las personas una teoría empírica, libre de valoraciones y desapasionada, de los órdenes jurídicos positivos. No se ocupa de lo que le gente debe moralmente hacer, si no que, en su lugar, se ocupa de reportar qué es lo que deben hacer desde el punto de vista o de acuerdo a cierto ordenamiento jurídico vigente.

5. Las filosofías de la justicia, y las teorías iusnaturalistas entre ellas, por el contrario, persiguen el objetivo de proveer a las personas razones para cumplir (completamente o bien hasta cierto punto), o no cumplir, con las reglas y estándares de los ordenamientos jurídicos positivos.

A la luz de estas consideraciones triviales, Positivo podría haber reaccionado de manera diferente a las objeciones de Natural. Por ejemplo, respecto de la objeción de Natural según la cual él (Natural) no obedecería la regla porque (Positivo) carecía de autoridad jurídica, podría haber respondido del siguiente modo:

¡A ver Natural, un minuto! Me parece, si es que puedo decirlo, que estás mezclando las cosas en tu argumento aparentemente sensato. Déjame tratar de explicar de qué se trata.

Aquí hay dos cuestiones diferentes en juego que deben mantenerse separadas.

Por un lado, está la cuestión teórica (descriptiva) que concierne a si, sobre la base de alguna visión empírica del derecho y libre de valoraciones, podemos afirmar que, de acuerdo con nuestra 
Constitución, yo tengo la autoridad jurídica para crear reglas, y también esta regla en particular.

Por el otro lado, está la cuestión práctica de si tú tienes el deber moral de obedecer las reglas que yo creo en mi carácter de legislador, y también de obedecer esta regla en particular.

En lo que respecta a la primera cuestión, nadie negaría que, desde el punto de vista de una teoría empírica del derecho positivo, según proponen los positivistas, aquí tenemos un sistema jurídico, donde alguien (yo mismo) tiene la autoridad jurídica para crear normas jurídicas. Esto podemos explicarlo en los siguientes términos: cuando nuestro padre Lex vivía, él y otras personas celebraron una convención constitucional relativa al modo adecuado para gobernar nuestra sociedad. Seguramente fue una convención jurídica, porque fue su objetivo proclamar y establecer un sistema jurídico, aunque, por supuesto, no mediante una autorización jurídica previa (Ex facto ius oritur: ¿no es así?). El resultado de esa convención fue la decisión de producir algunas normas constitucionales de acuerdo a las cuales: (i) Se proveyó a Lex el poder de crear normas y de aplicarlas; (ii) también se acordó que, a su muerte, Lex designaría a aquel que lo sucedería en el ejercicio de esas funciones. Desde entonces, la gente de nuestra sociedad se somete, en su mayoría, a las normas que Lex creó y también colaboran con los actos de aplicación. Lo mismo ocurrió cuando yo mismo ejercí los poderes de creación y aplicación de normas. Yo -junto con los oficiales de policía a los que he nombrado y pagado con fondos de las arcas públicas- tengo la fuerza necesaria para hacer cumplir las normas; yo también he firmado tratados con los pueblos vecinos relativos a los límites territoriales de nuestra comunidad (desde los Viñedos de los Caimanes hasta las cumbres del Monte Shibboleth).

Bien, en lo relativo a cómo el derecho positivo -y nuestro sistema jurídico- funciona, el problema del huevo y la gallina está mal planteado; es un claro reflejo de un calambre mental que requiere terapia filosófica. La existencia de casos claros, obvios, de sistemas jurídicos sugiere que, usualmente, la autoridad jurí- 
Una mirada desde el realismo analítico: vieja metafísica...

dica surge de algún hecho constitutivo, el cual se establece y es tenido en cuenta como un hecho jurídico. Como consecuencia, la alternativa que presentan los principios del huevo y la gallina es demasiado estrecha como para ser buena.

Vamos a ver:

Huevo: alguien tiene el poder de crear normas jurídicas si, y solo si, una norma jurídica existente le confirió ese poder.

Gallina: una norma que confiera el poder de crear normas jurídicas existe si, y solo si, alguien con el poder jurídico de crearla lo ha hecho.

Sin embargo, mediante un sencillo ejercicio de la imaginación, lo que ocurrió al alba de los ordenamientos jurídicos es algo como un fiat individual o colectivo como este:

"Nos, por medio de este acto, establecemos procedimientos para la creación y aplicación de reglas concernientes a nuestros comportamientos recíprocos y frente a otras gentes, tierras, comercios, etc. y llamamos a estos procedimientos, y a las reglas que surjan de ellos, derecho, nuestro derecho".

Por supuesto, también son posibles actos fundacionales del derecho con el carácter de revoluciones o golpes de estado:

"Nos, por medio de este acto, establecemos un nuevo procedimiento para crear y aplicar reglas jurídicas, y este será nuestro derecho de ahora en más".

Y puede ocurrir que las personas, en otros ordenamientos jurídicos, reaccionen del siguiente modo:

"Muy bien, hicieron eso. Pero vamos a ver si realmente tienen la fuerza y el apoyo popular necesario para hacer de su nuevo orden uno generalmente eficaz", o, en un contexto internacional de derechos humanos y anti soberanía: "Hiciste eso. Pero aunque tengas la fuerza para hacer eficaz tus reglas vamos a considerarlas jurídicamente nulas de manera absoluta, y consideraremos ilegal el ejercicio de tu poder político, porque 
eres responsable de graves violaciones a los derechos humanos. Tan pronto como podamos capturarte, tú y tus cómplices serán llevados a la Corte Penal Internacional, donde deberán responder por sus crímenes".

Para resumir: en vista de explicaciones tan simples sobre la existencia del derecho (o bien de cómo son posibles las autoridades jurídicas), los principios del huevo y la gallina tienen un olor de fundacionalismo mal planteado - y notamos, por cierto, que Kelsen, con su idea de la norma básica (Grundnorm) presupuesta o ficticia, vio esto claramente.

Por ende, parece posible proporcionar una solución razonable al problema teórico (descriptivo) acerca de si yo, Positivo, (y cualquier otra persona en el mundo) puede tener la autoridad jurídica para crear reglas - una vez que, lo repito, se adopte la perspectiva de una teoría del derecho empírica y libre de valoraciones.

Frente a esta conclusión, sin embargo, tú, Natural, podrías argumentar que, en lo que a nuestro sistema jurídico concierne, yo no tengo la autoridad jurídica para crear esa regla en particular, que impone un diezmo más gravoso. En otras palabras, puedes cambiar el tema, de uno aparentemente general, crucial, fundacional, metafísico y filosófico, concerniente a la mismísima "posibilidad" del derecho, a un problema de interpretación constitucional. ¿Acaso la convención constitucional fundante me da el poder de crear una regla con ese contenido, o bien una regla de ese tipo debe ser considerada insanablemente nula, ya que se encuentra más allá de los poderes conferidos? ¿Tengo el poder de crear solo normas razonables para nuestra comunidad, o puedo también crear cualquier tipo de regla que me plazca, incluso reglas irrazonables? ¿Quién, en todo caso, decidirá acerca de la razonabilidad de las reglas? Creo -pero esto es, claro está, un argumento llevado desde el punto de vista de un participante- que nuestra Constitución le confía al gobernante el poder de crear reglas razonables para la comunidad; también creo, sin embargo, que le confía al gobernante el poder absoluto de determinar si una regla es o no razonable para la comunidad. Desde este (práctico, interpretativo y argu- 
Una mirada desde el realismo analítico: vieja metafísica...

mentativo) punto de vista (desde un punto de vista empírico, un observador podría relevar que este es un tema nuevo para nuestra sociedad; que la interpretación constitucional nunca había sido un problema; que comportamientos pasados parecen sugerir que la gente no tiene, ni tenía, una idea clara acerca del poder creador de normas del gobernante, etc.), yo digo, para concluir, que de acuerdo con nuestra Constitución, si se la interpreta correctamente, tú, que eres un súbdito de esta comunidad jurídica, tienes el deber jurídico de cumplir con la regla del diezmo que yo creé, y a su vez yo tengo el poder de ordenártelo.

Ahora llegamos a la otra cuestión de que hablé al comienzo: es decir, la cuestión de si tú tienes el deber de cumplir con dicha regla; si, en términos más precisos, tú (también) estás moralmente obligado al cumplimiento (ya que, mediante una pregunta abierta, podemos siempre decir: "Bien, de acuerdo con el ordenamiento jurídico $O J$, yo tengo de hecho el deber jurídico de hacer $x$; pero, ¿debo yo hacer $x$ moralmente? ¿Estoy moralmente justificado a hacer $x$ ?). Lo deberes morales no pueden depender, en definitiva, sino de aquello a lo que nos comprometemos. Dependen, para cada agente moral, de su acto de elección moral última, con el cual él adopta las pautas que regulan su conducta frente a los demás, y su responsabilidad moral.

En este tema, yo diría -nuevamente, no por razones teóricas, sino como un participante comprometido- que nuestro sistema jurídico es moralmente bueno, que promueve el gobierno de la razón en los asuntos públicos, y que, en todo caso, la regla del diezmo no es tan irrazonable ni tan moralmente repugnante como para justificar el costo que la sociedad debería soportar debido a un acto de desobediencia ( $t u$ acto de desobediencia). Entonces, digo que no solo tienes de hecho el deber jurídico de hacer lo que te ordeno (en cuanto miembro de esta comunidad jurídica), sino que además (moralmente) debes hacerlo, por varias buenas razones que deberías aceptar. Por supuesto, puedes pensar distinto. Puedes defender una concepción distinta de lo que es el buen gobierno y la creación moralmente legítima 
Pierluigi Chiassoni

de normas. Tienes que tener en claro, sin embargo, que dichas posiciones no tienen nada que ver con la cuestión teórica acerca de si yo tengo, de hecho, alguna autoridad jurídica (y, de modo más general, con la cuestión acerca de la existencia empirica de los sistemas jurídicos y las autoridades jurídicas)".

Natural decide abandonar la comunidad, luego de haber aceptado el argumento de Positivo. Positivo le concede diez vacas y tres quintales de maíz. Phil es sentenciado a diez años de meditación en la cumbre del Monte Karnap. Exeunt omnes.

\section{Bibliografía}

Bobbio, N., Giusnaturalismo e positivismo giuridico, Milano, Comunità, 1965.

Carnap, R., "The Elimination of Metaphysics Through Logical Analysis of Language", trad. de A. Pap (www.ditext.com/carnap/elimination. html) del artículo original "Überwindung der Metaphysik durch Logische Analyse der Sprache", Erkenntnis, Vol. II, 1932.

Chiassoni, P., The Simple and Sweet Virtues of Analysis. A Plea for Hart's Metaphilosophy of Law, en "Problema", 5, 2011, pp. 53-80; una versión revisitada puede leerse en Chiassoni, P., El discreto placer del positivismo jurídico, Bogotá, Externado de Colombia, 2016, pp. 377-444.

Chiassoni, P., "Ruling Platitudes, Old Metaphysics, and a Few Misunderstandings About Legal Positivism", en Canale, D., Tuzet, G. (eds.), The Planning Theory of Law. A Critical Reading, Dordrecht - Heidelberg - New York - London, Springer, 2013, pp. 153-168.

Chiassoni, P., El discreto placer del positivismo jurídico, Bogotá, Externado de Colombia, 2016.

Dworkin, R., Law's Empire, London, Fontana, 1986.

Ferrajoli, L., La democracia a través de los derechos. El constitucionalismo garantista como modelo teórico y como proyecto politico, Madrid, Trotta, 2014. 
Hart, H. L. A. (1961), The Concept of Law, Second Edition, Oxford, Oxford University Press, 1994.

Hart, H. L. A., "Legal Positivism", en Edwards, P. (ed.), The Encyclopedia of Philosophy, New York, Macmillan, 1967.

Kant, E., Metaphysische Anfangsgründe der Rechtslehre de 1797 (trad. de G. Lizzaraga, Principios metafisicos del derecho, Librería de Victoriano Suarez, Madrid, 1873 - http://fama2.us.es/fde/ocr/2006/ principiosMetafisicosKant.pdf

Marmor, A., Philosophy of Law, Princeton - Oxford, Princeton University Press, 2011.

Marmor, A., The Language of Law, Oxford, Oxford University Press, 2014.

Raz, J., Ethics in the Public Domain. Essays in the Morality of Law and Politics, Oxford, Clarendon Press, 1994.

Raz, J., The Authority of Law. Essays on Law and Morality, Second Edition, Oxford, Oxford University Press, 2009.

Ross, A., "El problema de la validez y el positivismo jurídico", 1961, en Ross, A., El problema de la validez y otros ensayos, México, Fontamara, 1969, pp. 7-46.

Scarpelli, U., Cos'è il positivismo giuridico, Milano, Comunità, 1965.

Shapiro, S., Legalidad, Madrid-Barcelona, Marcial Pons, 2014, traducción de Papayannis, D. M. y Ramírez Ludeña, L.

Stavropoulos, N., Legal Interpretivism, en Stanford Encyclopedia of Philosophy, First Published Tue Oct 14, 2003; substantive revision Tue Apr 29, 2014. 